\title{
Hydrotherapy and Its Application in Oral Medicine
}

\author{
Riya Bhargava ${ }^{1}$, D.S.V. Sindhuja ${ }^{2}$, Poorvi $^{3}$ \\ 1,2, 3 Department of Oral Medicine and Radiology, Manav Rachna Dental College, Faridabad, Haryana, India.
}

\section{ABSTRACT}

When it comes to natural medicine, the use of water or hydrotherapy is as old as humankind. Hydrotherapy is also known as water therapy, pool therapy, balneotherapy and aquatic therapy. Water as a treatment aid was used in various parts of Rome, Greece, Egypt, China and Japan in the ancient period. Water therapy means using water for medicinal purposes like hot tubs, cold water treatments, ice packs, steam vapours, saunas, mineral springs, hot springs, wet towel applications, water exercises, and water massages. Therefore, the use of water at different temperatures and in different forms provides various effects on several systems of the body. Great results of hydrotherapy were experienced by people in physical functioning, energy, sleep, cognitive function, ability to work and participation in daily life. Based on the available data and literature this review propounds that water therapy has an empirical evidence-based outcome on various systems of the body.

\section{KEY WORDS}

Natural Medicine, Hydrotherapy, Empirical Evidence-Based, Various Systems.
Corresponding Author:

Dr. Riya Bhargava,

Manav Rachna Dental College,

Sector-43, Delhi-Surajkund Road,

Faridabad, Haryana, India.

E-mail: riyabhargava300@gmail.com

DOI: $10.14260 /$ jemds/2021/766

How to Cite This Article:

Bhargava R, Sindhuja DSV, Poorvi. Hydrotherapy and its application in oral medicine. $J$ Evolution Med Dent Sci 2021;10(44):3791-3797, DOI: $10.14260 /$ jemds/2021/766

Submission 20-08-2021,

Peer Review 10-11-2021,

Acceptance 17-11-2021,

Published 30-11-2021.

Copyright (C) 2021 Riya Bhargava et al This is an open access article distributed under Creative Commons Attribution License [Attribution 4.0 International (CC $B Y 4.0)]$ 


\section{BACKGROUND}

Water therapy or hydrotherapy is the use of water for treatment purposes at varying temperatures, both internally and externally. Also known as water therapy or "water cures," hydrotherapy includes therapeutic treatments such as saunas, steam baths, foot baths, contrast therapy, sitz bath. ${ }^{1}$ External or topical applications include cold or hot water packs, compresses, baths, pools, steams, sweats, showers, enemas, and colonics. Various thermodynamic properties of water affect an organism's circulation and metabolic functions, improve its capability to remove waste and eliminate on its own and regulate the environment. These techniques applied to a patient are a form of stress to the cells which provide an opportunity for the body's natural healing processes to take place. Hydrotherapy has a simple nature cure, a gentle, effective, and curative treatment modality for modern culture. ${ }^{2}$

\section{History}

Around 10,000 BC, Native Americans used hot water applications like sweat lodges for healing purposes. In Germany, the waters of Baden-Baden have been utilized for millennia. In India, since $5000 \mathrm{BC}$, Ayurvedic steam treatments have been used. Remains of an ancient bath were discovered in Pakistan, dating back as far as 4500 BC. On the island of Crete, travellers and visitors had access to public baths and running water and would bathe before visiting the king at the palace of Knossos in 2000 BC. The effects of colon hydrotherapy have been recorded since $1500 \mathrm{BC}$, according to the "Ebers Papyrus," an ancient Egyptian medical text. Hippocrates, known as the "Father of Medicine," around 400 BC, started using water for medicinal purposes. He recommended the utilization of baths in the therapy of both acute and chronic illness, and his works regarding baths contained probably the soonest proclamations on the medicinal uses of water. Two records revealed that water was used in the treatment of rheumatism, fever, inflammation, and other illnesses. The Greeks brought water treatments to the Roman Empire, and bathing became widespread in Rome by 50 BC. Roman physicians Galen and Celsus wrote about preventing diseases with warm and coldwater applications.

Many consider Vincent Priessnitz, an Austrian farmer born in the 1700s, to be the founder of modern hydrotherapy. He recommended variations of "water, food, and air" in place of conventional medicine as remedies for common illnesses. Word of his treatments and their successes travelled quickly, and because they were cheap and easy to do at home, they became very popular in Europe during his lifetime. ${ }^{3}$

\section{HYDROTHERAPY AND BALNEOTHERAPY IN} ORAL MEDICINE

\section{Oral Medicine}

Oral medication is a dental specialization that connects the conventional zones of health (wellbeing) among dentistry and medication, which is usually concerned about the diagnosis and the non-dental pathological management influencing the oral and maxillofacial region. ${ }^{4}$

The oral medication acts as a focus for professional interdisciplinary consideration of patients with manifestations emerging from the mouth that is not related to teeth. These manifestations are mostly chronic and may have a remarkable physical and psychological impact on the patient's life. In certain occurrences, signs and symptoms reflect issues confined to the mouth. ${ }^{5}$

\section{Hydrotherapy}

Hydrotherapy which is also known as aquatic therapy is the medicinal utilization of water, and the techniques include submerged walking or running, hot and cold-water therapy, water activities, etc. For many decades, water has been utilised for relieving pain, promoting relaxation and treating illnesses - and today we still use hydrotherapy for these purposes. Hydrotherapy strengthens the immune system, decreases inflammation, increases the healing of injured tissues and also increases the body energy, as it improves blood circulation. Hydrotherapy can also help psychologically as it produces endorphins and reduces tension. ${ }^{6}$

\section{Balneotherapy}

Balneotherapy is characterized as the utilization of warm mineral water at $20^{\circ} \mathrm{C}$ from natural springs with a $1 \mathrm{~g} / \mathrm{L}$ mineral content. ${ }^{7}$

\section{What is Thermal Spring Water?}

Thermal water is the water taken from natural springs which come from deeper layers under the ground, where it's warmed up by geothermal action. ${ }^{8}$

At the point when the warm water rises to arrive at the spring, it goes through rocks and soil which break down to add minerals to the water.

The most widely recognized solvent minerals incorporate calcium, bicarbonate, iron mixtures, silicates, sodium and magnesium salts, sulphur mixtures, and metals, alongside minor components like selenium. ${ }^{9}$

\section{How does Balneotherapy Work?}

The body's immune and hormone systems are impacted by hot mineral water, which has pain-relieving, antioxidant and anti-inflammatory effects.

- Reduces mucosal and skin inflammation.

- Hydrates mucosa and skin.

- Reverses damage caused by UV rays.

- Balances the microbiome.

\section{Oral Heat Therapy (Thermo-Hydrotherapy)}

Oral Heat Therapy which is also known as Liquid Heat Therapy is a supportive therapy that is effective for the following:

1. It promotes healing after oral surgery.

2. For treating infections.

3. To prevent infection during wound healing. 


\section{How does It Work?}

It produces vasodilatation by increasing tissue temperature, which increases the supply of nutrients, antibiotics, oxygen, and the elimination of metabolic waste and carbon dioxide. ${ }^{10}$

1. Antibiotics and immune system work more effectively as they increase the local circulation

2. After surgery, it promotes adequate drainage of stagnant blood

3. If there is an infection present, the heat which is produced by the therapy promotes proper drainage of infection.

\section{Step by Step Instructions to do Thermo-} Hydrotherapy

1. Gently flush within the mouth with warm-hot saline $(1 / 2$ teaspoon of salt to a $12 \mathrm{oz}$ glass of warm water). Do these a few times each day for a week after the medical procedure. Results are better if done more frequently. Take proper precautions to prevent burns.

2. Drink hot tea and before swallowing gently circulate the tea in the mouth.

3. Do these for few times each day for a week after a medical procedure or as prescribed. Do it as frequently as possible.

\section{Oral Mucosal Conditions}

OML's are abnormal alterations in surface aspect, colour, swelling, or loss of integrity of the mucosa. ${ }^{11}$

There can be painful/painless ulcerations, redness, irritation, swelling, papules, nodules, eroded pigmented regions which can be generalised or localised.

\section{Treatment of Oral Mucosal Conditions}

It includes drinking lots of water and others are: -

1. Using thermal spring water for mouth washing.

2. Taking gingival showers for thorough cleaning of the oral mucous membrane.

3. Oral hole for a calming and decongestive impact.

\section{Atopic Dermatitis and Eczema}

Atopic dermatitis is characterized as recurring skin symptoms which are inflammatory and are related to atopy. It is a long-lasting pruritic and inflammatory skin disorder that advances in flare-ups. There are two types of anomalies in this complex disease:

1. There is an alteration in the epidermal barrier which causes skin dryness and makes it sensitive to IgE allergens.

2. Oral manifestations include candidiasis, mouth breathing, odontogenic infections and can cause xerostomia due to medication.

Thermal spring water is used to reduce irritation and inflammation as water has specific hydrating properties. It is delivered through oral jet sprays and rinses.

It takes around $2-3$ weeks to reduce symptoms of dermatitis. Hydrotherapy gives positive effects even after the symptoms disappear and it also reduces the chances of flare ups. $^{12}$

\section{Psoriasis}

It is a chronic, scaly and inflammatory disease of skin which is genetically linked. Oral manifestations are uncommon and are frequently hard to diagnose. Such type of dermatosis is usually chronic, accompanied by flare ups and remissions with varying lengths, when persisting lesions are minimal. ${ }^{13}$

\section{Oral Manifestations ${ }^{14}$}

- They appear as small whitish bumps which when scraped may bleed.

- $\quad$ Red and white plaques are also seen.

\section{Treatment ${ }^{15}$}

- Thorough cleaning of lesions.

- Reduction in inflammation and gradual elimination of lesions.

- Possible suspension of local treatment.

\section{Burns and Scarring}

There are many causes which can result in oral burns and scarring.

Types:

1. Electric burns.

2. Thermal burns.

3. Chemical burns.

They can be iatrogenic or at home burns. ${ }^{16}$

Frequent causes of non-transient, non-keratotic white lesions are burns of oral mucosa.

Facial burns range from minor abuses to extreme debilitating wounds. More than half of wounds include the head and neck area and can be brought about by fire, electrical flow, steam, hot materials, and chemical substances. ${ }^{17}$

\section{Management with Hydrotherapy}

Hydrotherapy procedures like showers under running water and immersion in tub contributes in healing process. ${ }^{18}$

To combat with inflammatory reaction signs, hypertrophy, abnormal pigmentation and more precisely, redness and scarring, this therapy utilizes hot spring water and water jets which are enriched with minerals with varying hydropressure.

\section{Mechanism}

The dynamic impact of high-pressured water diminishes pruritis and it stimulates the nerve endings under the scar which produces an analgesic effect.

We could likewise hypothesize that during the initial months to years the scar formed due to burn is permeable to water and, thus, the oligo-elements present in water penetrate the scar and after reaching the superficial dermis they could modify inflammation and have a chemical impact on pruritis. It also contributes in rebuilding the collagen and elastin strands of scarred tissue, advancing the formation of flexible mucosa and skin. ${ }^{19}$ 


\section{Reasons to Administer Hydrotherapy in Oral} and Facial Burns

- It cleans the wound area and enhances desloughing.

- It helps in pus drainage and debridement.

- It alters bacterial flora.

- It promotes healthy tissue development and healing.

- It makes physical therapy easier.

- It provides comfort and uplifts the patient psychologically.

\section{Techniques}

1. Use of sterilized warm water along with povidone-iodine scrub will give comfort and quickly recognizable improvement in scarring, whatever may be its cause.

2. The mucosal healing process is accelerated with the help of thermal techniques and thermal spring water.

\section{Indications}

\section{In Case of Facial Burns and Scarring}

- Scarring related to burns both before and during the recovery (bridging, thick skin)

- Hypertrophic and keloid scars (thickening, irritation)

- Atonic wounds (without inclination for unconstrained healing)

Aftercare for dermatological procedures (derma abrasion, laser) where optimum skin healing is required.

\section{Anticipated Benefits}

- It fastens the skin healing process

- Due to its massage action, it helps in softening damaged mucosal zones and skin, preventing the formation of hypertrophic scars and mucosa and skin ridging.

- It lessens itching and inflammation.

\section{Head and Neck Cancer Rehabilitation}

Procedures such as chemotherapy and radiotherapy that are used to treat cancer can lead to weakened, hyperactive, damaged, dry, and sometimes burnt skin. Hydrotherapy can be used to treat them. Making tough situations simpler and re-establishing well-being and comfort to the mucous membrane and skin.

Patients who receive treatment for head and neck cancer experience some complications. Mucositis (red and inflamed mucous membrane), bleeding, pain, and infection are the most common problems which occur after chemotherapy and radiotherapy.

Radiotherapy to the head and neck may damage salivary glands as they are sensitive to radiation leading to xerostomia and also, it causes trismus (lock-jaw) as it damages the joints and muscles of the neck and jaw. These procedures may lead to maxillary or mandibular bone hypovascularization (decrease in blood supply). Also, it can cause other dental diseases like caries or any other soft tissue complication. It can even cause osteoradionecrosis (bone death).

The risk of infection may increase if there is any preexisting oral condition. Issues like broken teeth, calculus, and tartar, the quality, and condition of existing dental repairs like crowns or fillings, periodontal diseases and appliances like partial dentures or bridges, or other removable appliances can make treatment more troublesome later on. When the immune system is weak, the fungi and bacteria may develop an infection in the mouth.

Hydrotherapy is encouraged to prevent these complications and maintain the healthy state of oral tissues with the goal that no superadded contaminations can occur. ${ }^{20}$

\section{Oral Hydrotherapy Treatments}

Water's buoyancy produces an effect on the musculoskeletal system, which moves into the oral cavity and face more comfortable.

Sprays of warm water increase the range of motion and flexibility, relax the muscles, and can help individuals in getting facial exercise despite their physical restrictions.

It is effective for individuals with swelling as it generates a compressive effect due to the hydrostatic pressure of hydrotherapy which reduces the swelling. This water pressure factor can likewise eliminate the requirement for compression sleeves, which are other basic solutions for treating swelling. What's more, the hydrostatic pressure factor gives obstruction that fortifies muscles and improves muscle conditioning.

- Mouth washing shower.

- Oral splash.

- Gingival shower.

- Facial treatment with emollient cream.

- Complete scalp treatment.

\section{Oral Lichen Planus}

It is the most commonly occurring oral dermatosis and the most frequently found mucosal pathosis.

It is a chronic mucocutaneous disease that affects the oral mucous membrane. It is an autoimmune, T-cell mediated disease in which the cytotoxic CD8+T cells cause apoptosis of the basal layer of the mucosal epithelium. ${ }^{21}$

\section{Anticipated Benefits}

- Very quick relieving impacts of thermal spring water under flexible tension.

- Healing in stripped mucosal and skin territories.

- Long-lasting remission.

\section{Cutaneous and Mucosal Lichen Planus}

Lichen planus in cutaneous form causes mainly itching and in its mucous form, the symptoms and signs are more troublesome. There may be tissue erosion and even atrophy that can cause bleeding and pain. Brushing teeth becomes difficult or eating certain foods. Two factors on which hydrotherapy works are itching and erosion.

\section{Indications for Hydrotherapy in Disorders of the Mouth and Tongue Mucosa}

- Chronic and subacute gingivitis and stomatitis

- Chronic aphthous 
- Glossitis (swelling of the tongue because of different causes)

- Glossopyrosis (burning mouth syndrome)

- Oral lichen planus (erosive, erythematous)

\section{Along with Drinking Cure, Other Specialized Treatments Given are}

- Mouth washing with the use of thermal spring water

- Gingival showers to clean and massage the mucosa.

- Spraying the oral cavity for decongesting and antiinflammatory benefits.

- Compresses applied to mouth injuries, soaked in thermal spring water.

\section{Anticipated Benefits}

The functional symptoms of OLP and erythema are significantly reduced by the use of thermal spring water. ${ }^{22}$

A half-year after the finish of the hydrotherapy treatment, 74 $\%$ of patients quit utilizing topical corticosteroids, $66 \%$ no longer utilized corticosteroid mouthwash and $98 \%$ had no requirement for analgesics. ${ }^{23}$

\section{Seborrheic Dermatitis, Rosacea, Couperose}

'Dermatitis' is a red, bothersome, flaky (excited) skin grumbling; 'seborrheic' implies that the rash influences oily (sebaceous) skin zones like the face, scalp, and focus of the chest.

Facial seborrheic dermatitis (FSD) is a relapsing, persistent inflammatory skin condition that affects regions of the face with a lot of sebaceous glands. It appears as erythematous scaly macules or plaques that are sometimes accompanied by pruritus.

It usually affects the inner brows and the creases across the cheeks and nose on the face. Red, inflamed, and flaky eyelids are also common (seborrheic blepharitis). ${ }^{24}$

Rosacea, also referred to as coupe rosé, is a benign skin disease that produces chronic redness on the cheeks, nose, and quite often on the forehead and chin area.

Tingling sensations, specifically around the eyes, accompany these symptoms. In the infected areas that are associated with telangiectasia, small blood vessels, which are typical of varicosities, are often visible. ${ }^{25}$

Hydrotherapy can be used to treat these dermatological diseases.

\section{Temporomandibular Dysfunction Syndrome}

TMJ (temporomandibular joint and muscle disorders) refers to a category of diseases characterized by pain and weakness in the jaw joint and muscles that regulate jaw movement.

There may be pain, functional issues ranging from minor discomfort to significant functional limitations, and/or structural modifications, such as changes to the articular surfaces and muscle arrangements. ${ }^{26}$

Hydrotherapy was introduced to improve local circulation by alternating arteriole and capillary vasodilation and vasoconstriction. Since the patient's TMD may be chronic (indicating heat treatment) or aggravating conditions like clenching and grinding can induce inflammation, vascular flush (also known as contrast treatment) may be preferred overheat or cold alone.

\section{Method}

For ten minutes, apply moist heat with a towel that is placed beneath hot water to the painful area, then with the help of an ice cube, wrapped in a washcloth, lightly brush the area, until the area becomes numb.

Do this thrice, finishing with a cold application. ${ }^{27}$

\section{Limitations and Considerations in Water Exercise Therapy}

Water-based exercises should only be done under the supervision of a certified health practitioner for many back pain sufferers. If a person has any of the following conditions, water treatment should be avoided:

- Fever.

- Severe heart failure.

- Incontinence.

- Infection.

The temperature of the water may be too warm for particular circumstances. Water treatment is usually done in pools or tanks with water that is 90 to 94 degrees (Fahrenheit), which is almost as warm as bathwater, to enhance blood circulation. As a result, individuals with any of the illnesses listed above should avoid or limit their water therapy activity, or ensure that the pool or tank they use is colder to prevent exacerbating their symptoms.

Individuals with extremely restricted endurance or range of motion may be unable to negotiate a tiled (and slippery) pool apron safely enough to engage in a water therapy exercise programme. To avoid this risk, rubber mats are frequently utilised to boost traction.

Refraction affects the perception of things (such as the trainer teaching exercises) in water, making it harder for those with poor eyesight or impaired sense of body position or balance due to stroke or other damage to acquire certain motor skills.

Finally, the buoyancy supplied by water may not be as useful for bone growth as weight-bearing land-based workouts for people with poor bone density or osteoporosis. The increased strength and balance gained through an aquatic training programme may allow for a safe transition back to land-based activity, which is better for bone strength. ${ }^{28}$

Internal cleansing treatments such as douching, colonic irrigation, and enemas are not widely recognised since they can injure a person by disrupting the natural balance of the digestive system and vagina.

Some individuals who use essential herbs and oils in their bath water may experience an allergic response known as contact dermatitis as a result of hydrotherapy.

The most common negative effect of hydrotherapy is overheating, which may be quite dangerous. When a person spends too much time in a hot tub or jacuzzi, this might happen. ${ }^{29}$ 


\section{Post Treatment Guidelines}

Following hydrotherapy, there are no special post-treatment instructions. It's important to remember to put the patient at ease for a few hours following the therapy. Work that requires a lot of effort should be avoided. It's also important to keep the patient warm following the treatment because there's always a risk of acquiring cold.

\section{Recovery Time}

This therapy does not have a set recovery time. If the individual feels comfortable doing so, he or she can leave. Although it is up to the practitioner to assess the severity of the illness and determine the healing duration.

\section{Precautions for Hydrotherapy}

It's important to keep an eye on the water temperature since it might cause serious burns. The temperature of the water should be monitored and adjusted to within the tolerance range. The water tolerance level must be adjusted based on the therapy, body temperature, and injury or sickness. If the water is extremely hot or cold, it should be administered using a towel or barrier to keep the skin from getting burnt. ${ }^{30}$

\section{Use of Hydrotherapy in COVID-19}

In the recent past, the entire human civilization has encountered the most terrifying pandemic, the so-called Covid-19, which placed a sudden surge of medical help and guidance over a very short period. ${ }^{31}$ Owing to the limitations we have in modern medicine in such times of increased health care demand, alternative and contemporary treatments may play a vital role in treating such unidentified and unexplained illnesses.

Hydrotherapy can play an important role in alleviating covid symptoms and for supportive treatment. Heat therapies such as steam baths, saunas, or hot baths using water from $92^{\circ} \mathrm{F}$ to $104^{\circ} \mathrm{F}$ tend to be connected with a decreased incidence of viral infections and lower mortality rates from viral illnesses when used for 5 to 20 minutes followed by cold treatments as shown by the Finnish and Estonian populations. The use of these modalities does not need the purchase of costly equipment. Building a sauna or paying to use one can be costly, but hydrothermotherapy can be done with inexpensive equipment like pails, towels, and hot water, all of which are readily available across the world. Water, a means of heating water, a large kettle with a cover for steam, towels, a container for a foot bath, and a chair or stool are all examples of home heat treatment methods.

As a result, we believe that repeated heat followed by cold treatments are the most effective first-line therapy for mild to moderate coronavirus 2 infections. We also anticipate that if a large number of people in each community adopt this strategy, the impact of coronavirus 2 on the global population will be considerably reduced. ${ }^{32}$

Raising your body temperature can aid in the prevention of viral illnesses. This is the role of a fever, which naturopathic medicine has traditionally considered to be one of the most significant symptoms to be treated rather than repressed. Temperature controls up to 102-103 degrees (rather than fever suppression) is often a safe (patient- specific) way to help the body fight illness. Heat suppresses infections, boosts the immune system's innate and adaptive defences, and activates regulatory systems that reduce inflammatory reactions while limiting tissue damage.

Combining heat and cold for preventive and immune support may also be effective. During the 1918 pandemic, persons who took hot baths followed by a quick cold bath had reduced viral infection rates and fatality rates, according to the research. Its use in COVID-19 is still being investigated, but it is expected to have comparable benefits. The increased immune activity in response to heat and cold treatments is thought to be the cause of this physical reaction to hydrotherapy. ${ }^{33}$

\section{Transitioning to a New Level of Hydrotherapy Education}

In terms of curriculum and graduate schools, hydrotherapy has been associated with both mainstream and alternative medicine. Many traditional institutions have recently embraced the hydrotherapy course, which has been offered for several decades. In addition, hydrotherapy students participate in residency programmes and training in hospitals where traditional education is the norm. This may improve graduate interaction and mutual respect, allowing them to collaborate and work together toward the same goal: the "pharmaceutical care model." To summarise, the high quality of clinical trials and mega trials were done in hydrotherapy, as well as changes in curriculum and residency programmes, have contributed to the growth and acknowledgement of hydrotherapy as a viable alternative therapeutic option.

\section{CONCLUSIONS}

Based on the available literature, this review suggests that hydrotherapy has been in use since the beginning of mankind and has provided profound effects on the human body and for the cure of several medical conditions. This review focuses on the application of hydrotherapy in oral medicine and is widely used in the treatment of oral mucosal conditions, atopic dermatitis and eczema, psoriasis, burns and scarring, head and neck cancer rehabilitation, oral lichen planus, seborrheic dermatitis, rosacea, coupe rosé and temporomandibular dysfunction syndrome.

Last but not the least, hydrotherapy is gaining popularity among alternative therapies for alleviating covid-19 symptoms which is still in the study. Nevertheless, it carries a huge scope as a treatment modality for many new, unexplained illnesses.

Although it has several applications, one of the limitations of hydrotherapy is that there is a lack of explanation on the mechanism of how it improves these conditions which facilitates further studies to collect the evidence for its mechanism.

The goal of this review article is to assist researchers in determining whether or not hydrotherapy is an effective therapy that may help improve and treat a variety of ailments. More studies are required to close the gap in research and education so that the alternative hydrotherapy system may be fully integrated with the traditional system. 
Financial or other competing interests: None.

Disclosure forms provided by the authors are available with the full text of this article at jemds.com.

\section{REFERENCES}

[1] https://www.verywellhealth.com/different-types-ofhydrotherapy-89993

[2] https://www.sciencedirect.com/sdfe/pdf/download/eid /3-s2.0-B9780323430449000406/first-page-pdf

[3] Bahadorfar M. A Study of hydrotherapy and its health benefits. International Journal of Research, 2014;1(8):294-305. Retrieved from https://journals.pen2print.org/index.php/ijr/article/vie $\mathrm{w} / 507 / 148$

[4] Schmidt-Westhausen AM, Bornstein MM. Oral medicine: a specialty placed between medicine and dentistry. Bundesgesundheitsblatt Gesundheits for schung Gesundheitsschutz 2011;54(9):1061-5.

[5] https://www.ouh.nhs.uk/omd/oral-andmaxillofacial/oral-medicine.aspx

[6] https://clearcomfort.com/blog/lymphedemahydrotherapy-treatment/

[7] Özgöçmen S. Nonpharmacologic management of axial spondyloarthritis Chap- 13. In: Mease P, Khan M, eds. Axial spondyloarthritis. $1^{\text {st }}$ edn. Elsevier 2019:203-16.

[8] https://labmuffin.com/what-is-thermal-water-and-howdoes-it-work-in-skin-care

[9] https://www.healthline.com/health/beauty-skincare/thermal-water\#takeaway

[10] https://www.piads.org/surgical-instructions/oral-heattherapy-thermo-hydrotherapy-3/

[11] Toum SE, Cassia A, Bouchi N, et al. Prevalence and distribution of oral mucosal lesions by sex and age categories: a retrospective study of patients attending lebanese school of dentistry. Int J Dent 2018;2018:4030134.

[12] https://www.fondationeczema.org/en/treatment/hydro therapy-and-eczema

[13] Khan S, Zaheer S, Gupta ND. Oral psoriasis: a diagnostic dilemma. European Journal of General Dentistry 2013;2(1):67-71.

[14] https://www.colgate.com/en-us/oral-health/immunedisorders/how-to-treat-your-psoriasis-mouthsymptoms

[15] https://www.avenecenter.com/en/treatment/atopicdermatitis-eczema

[16] https://www.slideshare.net/alidosoky3/oral-burn

[17] Bruns AD, Meyers AD. Facial burns. 2021. https://emedicine.medscape.com/article/879183overview

[18] Lochaitis A, Chalikitis S, Tzortzis C. Hydrotherapy (bath therapy) as a treatment option in burns. Annals of the MBC 1992;5(2).
[19] Moufarrij S, Deghayli L, Raffoul W, et al. How important is hydrotherapy? Effects of dynamic action of hot spring water as a rehabilitative treatment for burn patients in Switzerland. Annals of burns and fire disasters 2014;27(4):184-91.

[20] https://oralcancerfoundation.org/complications/

[21] Lavanya N, Jayanthi P, Rao UK, et al. Oral lichen planus: an update on pathogenesis and treatment. J Oral Maxillofac Pathol 2011;15(2):127-32.

[22] Nocera T, Jean-Decoster C, Georgescu V, et al. Benefits of Avène thermal hydrotherapy in chronic skin diseases and dermatological conditions: an overview. J Eur Acad Dermatol Venereol 2020;34 Suppl 5:49-52.

[23] Boisnic S, Branchet MC, Ben Slama L, et al. Traitement du lichen plan buccal érythémateux et Eau thermaled'Avène. Act OdontoStomatol 2004;225:57-64.

[24] https://www.bad.org.uk/shared/getfile.ashx?id=180\&it emtype $=$ document

[25] https://www.mayoclinic.org/diseasesconditions/rosacea/symptoms-causes/syc-20353815

[26] Laplanche 0, Ehrmann E, Pedeutour P, et al. TMD clinical diagnostic classification (Temporo Mandibular Disorders). J Dentofacial Anom Orthod 2012;15(2):202.

[27] Pierson MJ. Changes in temporomandibular joint dysfunction symptoms following massage therapy: a case report. Int J Ther Massage Bodywork 2011;4(4):3747.

[28] Andrew Cole M. Water exercise therapy limitations and considerations. Retrieved 13 November 2021, from https://www.spine-

health.com/wellness/exercise/water-exercise-therapylimitations-and-considerations

[29] Hydrotherapy: benefits, risks, side effects, types, contraindications. (2021). Retrieved 13 November 2021, from https://www.epainassist.com/alternativetherapy/what-is-hydrotherapy

[30] Hydrotherapy: treatment, procedure, cost, recovery, and side effects. (2021). Retrieved 13 November 2021, from https://www.lybrate.com/topic/hydrotherapy

[31] Bhargava R, Ghiloria A, Kapoor P, et al. Covid-19 vaccination - a saviour from pandemic. J Evolution Med Dent Sci 2021;10(38):3424-9.

[32] Ramirez FE, Sanchez A, Pirskanen AT. Hydrothermotherapy in prevention and treatment of mild to moderate cases of COVID-19. Medical Hypotheses 2021;146:110363.

[33] A vital yet underused method for COVID-19 prevention. (2021). Retrieved 13 November 2021, from https://www.psychologytoday.com/us/blog/rhythmsrecovery/202009/vital-yet-underused-method-covid19-prevention 